\title{
The largest reported papillary thyroid carcinoma arising in struma ovarii and metastasis to opposite ovary: case report and review of literature
}

Mohamed S. Al Hassan ${ }^{1}$, Tamer Saafan ${ }^{1 *}$ (D), Walid El Ansari ${ }^{2,3}$, Afaf A. Al Ansari ${ }^{4}$, Mahmoud A. Zirie ${ }^{5}$, Hanan Farghaly ${ }^{6}$ and Abdelrahman Abdelaal ${ }^{1}$

\begin{abstract}
Background: Malignant struma ovarii (MSO) is a very rare, germ cell tumor of the ovary, histologically identical to differentiated thyroid cancers. Struma ovarii (SO) is difficult to diagnose on clinical basis or imaging and is mostly discovered incidentally, with few published cases in the literature.

Case presentation: A 42-year old primiparous woman presented with abdominal pain and midline pelvic palpable firm mass arising from the pelvis. Imaging showed pelvic solid cystic mass. Total abdominal hysterectomy, bilateral salpingo-oopherectomy (TAH BSO) and infracolic omentectomy were performed. Histopathology revealed left ovary papillary thyroid carcinoma (PTC) arising in SO $(11 \mathrm{~cm})$ and metastatic papillary thyroid carcinoma in the right ovary. Thyroid functions tests were all normal, ultrasound thyroid showed two complex nodules in the left thyroid lobe. Total thyroidectomy was decided, but the patient refused further surgical management and was lost to follow up as she left the country. We undertook a comprehensive literature search, and MSO and thyroid management data from 23 additional publications were analyzed and tabulated. This PTC MSO is probably the largest reported in the literature.

Conclusions: Among the different surgeries for MSO, TAH + BSO appears to have the best clinical outcome. However, unilateral salpingo-oopherectomy/ unilateral oophorectomy and bilateral salpingo-oopherectomy also seem effective. Ovarian cystectomy alone seems associated with higher recurrence. There remains no consensus on the associations between MSO tumor size and potential extent of metastasis, and about the management of thyroid gland. However, surveillance and thyroid gland work up to detect concurrent thyroid cancer are recommended.
\end{abstract}

Keywords: Total abdominal hysterectomy, Oopherectomy, Salipingo-oopherectomy, Thyroid cancer, Malignant struma ovarii, Papillary thyroid carcinoma, Follicular thyroid carcinoma

\footnotetext{
* Correspondence: tsaafan@gmail.com

'Department of General Surgery, Hamad General Hospital, Doha, Qatar

Full list of author information is available at the end of the article
}

(c) The Author(s). 2018 Open Access This article is distributed under the terms of the Creative Commons Attribution 4.0 International License (http://creativecommons.org/licenses/by/4.0/), which permits unrestricted use, distribution, and reproduction in any medium, provided you give appropriate credit to the original author(s) and the source, provide a link to the Creative Commons license, and indicate if changes were made. The Creative Commons Public Domain Dedication waiver (http://creativecommons.org/publicdomain/zero/1.0/) applies to the data made available in this article, unless otherwise stated. 


\section{Background}

Struma ovarii (SO) is a specialized or monodermal teratoma predominantly composed of mature thyroid tissue (thyroid tissue must comprise $>50 \%$ of overall tissue) [1]. SO accounts for $\approx 5 \%$ of all ovarian teratomas [2-4]. Histologically, SO can be benign or malignant [5], although malignant struma ovarii $(\mathrm{MSO})$ is rare $(<5 \%$ of cases), and metastasis is rare $(0.3-0.5 \%)[6,7]$. SO is difficult to diagnose on basis of clinical manifestations or imaging, and most cases are incidental findings in patients aged 40-60 years, with a mean age of diagnosis of 43 years $[4,5,8]$.

Common presenting symptoms include abdominal pain (20.6\%), palpable lower abdominal mass (23.5\%), vaginal bleeding $(8.8 \%)$, or asymptomatic $(41.2 \%$, tumor discovered by routine ultrasound). Tachycardia and ascites are sometimes present (12\%, 16\% of patients respectively). Clinical and biochemical features of hyperthyroidism are uncommon in women with SO $(<5-8 \%$ of cases) $[3,5,6]$, and whilst some reports observed no SO patients with overt hyperthyroidism symptoms (hence no thyroid function tests undertaken), others found 5-8\% incidence of hyperthyroidism with $\mathrm{SO}[4,9,10]$. SO women with hyperthyroidism can also have goiter and/or Grave's disease, but the incidence is very rare $[11,12]$. Seldom, seeding of the peritoneum by a benign tumor can occur (strumosis), which may present with ascites with or without pleural effusion $[13,14]$.

As for imaging, ultrasound appearance of SO may be as heterogeneous uni/multilocular solid mass or multilocular cystic masses [15-17]. An ultrasound feature of $\mathrm{SO}$ is the presence of one or more well circumscribed roundish areas of solid tissue with smooth surface 'struma pearls', often vascularized at Doppler examination, but otherwise similar (but not identical) to the 'white ball' comprising hair and sebum usually seen at ultrasound of dermoid cysts [17].

In women presenting with a pelvic mass, $\mathrm{SO}$ is typically diagnosed postoperatively based upon histologic findings of thyroid follicles in the resected ovary, where the histological pattern may show micro/macrofollicular or oxyphil adenoma, with/without papillary hyperplasia $[12,18]$. As in thyroid gland follicular tumors, the thyroid epithelium in the teratoma may be organized in a solid, embryonal or pseudotubular pattern, rather than thyroid follicles [19].

We present an extraordinary case of a primiparous woman with large SO containing papillary thyroid carcinoma, with metastasis to the contralateral ovary. To the best of our knowledge, this narrate is the first published case report of possibly the largest papillary thyroid carcinoma in SO with metastasis to the opposite ovary. Ethics approval and consent to publish were provided (Medical Research Centre review board, IRB, \#16024/16, Hamad Medical Corporation, Doha, Qatar).

\section{Case presentation}

A 42-year-old Indonesian female, presented at Hamad General Hospital in Doha, Qatar complaining of an on and off lower abdominal pain mainly in the right iliac fossa. She had a normal delivery 15 years ago, had regular menstrual cycles, and no previous medical illnesses.

\section{General examination}

She was vitally stable, with no significant lymphadenopathy or pedal edema. Abdominal examination revealed midline palpable firm mass with mild tenderness. The mass arose from the pelvis, extending $2 \mathrm{~cm}$ below the umbilicus. There was no ascites. Complete blood picture, renal and liver function tests were normal except for hemoglobin of $11.7 \mathrm{~g} / \mathrm{dl}$, and CA 125 was elevated (251 KU/L).

\section{Investigations}

Abdominal ultrasound showed a large solid cystic mass in the right adnexa region, reaching the midline $(\approx 6 \times 13$ $\mathrm{cm}$ ) with mild vascularity in the solid component. Both ovaries were not separately visualized. There was mild left hydrosalpinx and mild ascites. Transvaginal ultrasound did not show the left ovary, but the right ovary was visualized separately $(2.5 \times 2.1 \mathrm{~cm})$ and confirmed the presence of complex solid cystic mass in the middle of the pelvis. The mass $(13.5 \times 9.8 \mathrm{~cm})$ extended to the left adnexa, with cystic area $(9.2 \times 5.9 \mathrm{~cm})$ and a solid component $(9.1 \times 7 \mathrm{~cm})$ that had increased vascularity. Further chest/abdomen/pelvis CT and MRI (Fig. 1) confirmed the size and solid/ cystic nature of the mass and showed no metastatic lesions, and also deviation of uterus to the left side.

\section{Management}

The patient's clinical picture was discussed at our gynecologic multidisciplinary meeting and total abdominal hysterectomy (TAH), bilateral salpingo-oopherectomy (BSO) and lymphadenectomy were decided. Patient underwent $\mathrm{TAH}+\mathrm{BSO}$ plus infracolic omentectomy. During surgery, a freely mobile left ovarian mass was found with irregular surface and intact capsule. Right adnexa and uterus were normal. Patient had a smooth post-operative recovery and was discharged. Microscopic examination revealed an $11.0 \mathrm{~cm}$ left ovarian papillary thyroid carcinoma arising in SO (Figs. 2 and 3), with metastatic papillary thyroid carcinoma to the right ovary. No malignancy was found in right fallopian tube, uterus or cervix and there were negative lymph nodes. Following the histopathology results, patient had thyroid 


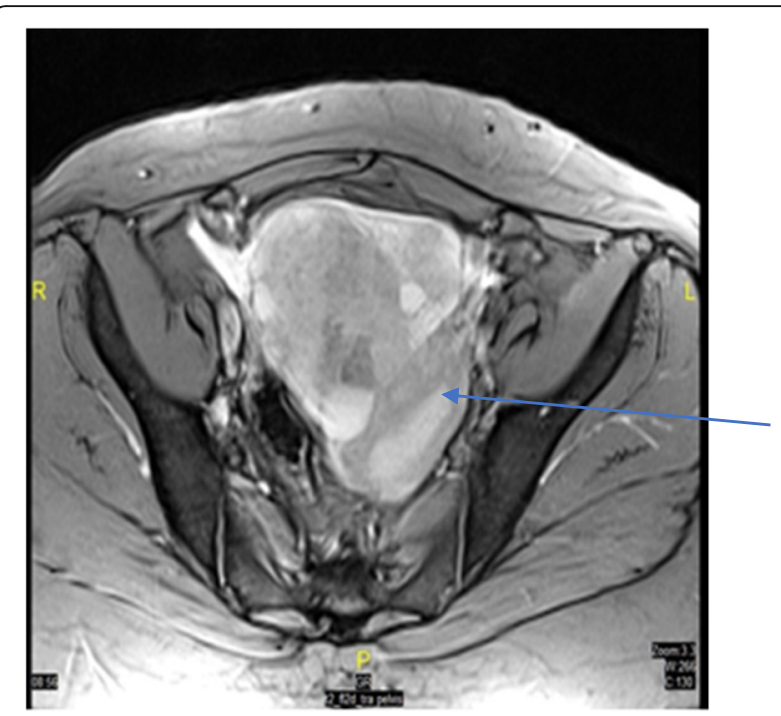

Fig. 1 Transverse T2 MRI section. The section shows well-defined complex lesion (arrow) with solid and cystic contents in the pelvis, extending on either side of the midline reaching to both sides of adnexa and measuring $13 \times 9.4 \times 8.1 \mathrm{~cm}$. Ovaries are not seen separately from the lesion. Uterus shows mild deviation to the left side due to pressure effect from the mass. No obvious lymph nodes or signs of metastasis

function tests (TSH, free T4, thyroglobulin) that were all normal. Thyroid ultrasound revealed $7 \times 11 \mathrm{~mm}$ complex nodule, a $6 \times 6 \mathrm{~mm}$ complex nodule and a $3 \times$ $4 \mathrm{~mm}$ cyst in the left thyroid lobe. No lesions were observed in the right thyroid lobe. The patient's clinical findings were discussed at our thyroid multidisciplinary meeting where total thyroidectomy and radioactive iodine therapy were decided; however the patient refused further surgical management, and was lost to follow up as she left the country.

\section{Pathologic findings}

Upon histopathologic examination, a papillary thyroid carcinoma was identified arising in SO tumor $(11.0 \mathrm{~cm}$ in greatest dimension) of the left ovary (Figs. 1, 2a and b), and a small metastatic focus measuring $0.1 \mathrm{~cm}$ in the right ovary. There was no malignancy in right fallopian tube, uterus or cervix and negative lymph nodes. Thyroglobulin immunohistochemical stained section highlighted the thyroid tissue in a background of ovarian tissue with $\mathrm{SO}$, and confirmed the origin from thyroid tissue (Fig. 3). AJCC Pathologic tumor staging was $\mathrm{p}$ T1b and FIGO stage was IB.

\section{Discussion}

$\mathrm{SO}$ is an uncommon ovarian tumor with $<5 \%$ malignancy, $5-23 \%$ metastasis, and $7.5-35 \%$ recurrence rates $[3,6,15$, 20]. Our comprehensive literature review of MSO, details


Fig. 2 Low and High power hematoxylin and eosin-stained section. a Low power hematoxylin and eosin-stained section (4x) demonstrates thyroid follicles of papillary carcinoma arising in benign thyroid follicles of SO. $\mathbf{b}$ High power hematoxylin and eosinstained section (60X) demonstrates papillary thyroid carcinoma with follicular pattern. Nuclear features including nuclear groves, clearing, overlapping and enlargement, consistent with papillary thyroid carcinoma arising in a SO

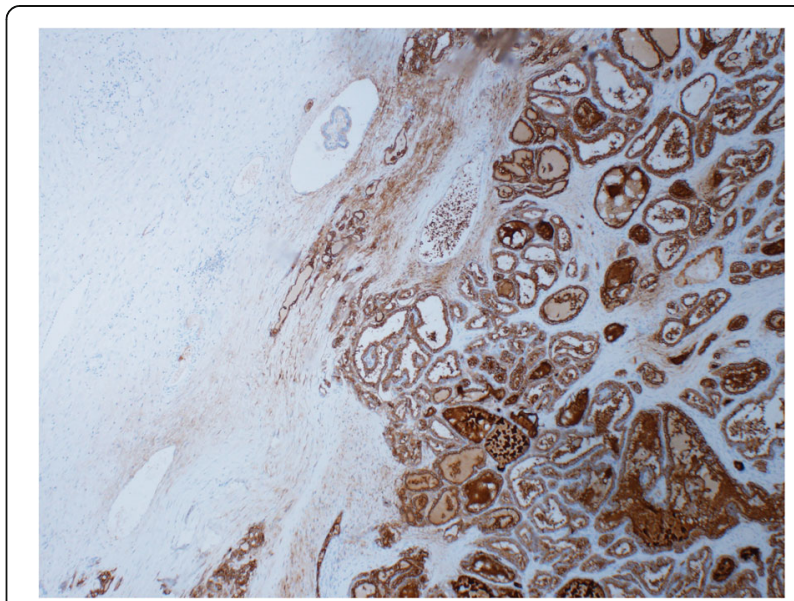

Fig. 3 Thyroglobulin immunohistochemical stain. Low power thyroglobulin immunohistochemical stained section (4x) highlights the thyroid tissue in a background of ovarian tissue with $\mathrm{SO}$ 
a wide range of parameters in relation to MSO that include: size, histopathological categories, type of gynecological surgery, thyroid gland workup and management, and MSO follow up and recurrence (Table 1).

Regarding the tumor size of MSO, a range of dimensions $(0.1-4.2 \mathrm{~cm})$ has been reported (Table 1), and an analysis of large series of $68 \mathrm{MSO}$ patients observed a mean tumor size of $5.28 \mathrm{~cm}$ [8]. To the best of our knowledge, our MSO is the possibly the largest $(11 \mathrm{~cm})$ reported MSO with PTC tumour confirmed by histopathology to date. Others found a MSO measuring $20 \mathrm{~cm}$, but did not report the tumor histopathology; hence we are unable to judge their tumor subtype [8]. Our MSO is also first to be reported from the Middle East and North Africa region. Such a large sized tumor is likely to cause pressure effects (as observed in our patient who had deviation of uterus to the left side) (Fig. 1).

As for the relationship between tumour size and metastasis, research [21] reported that a larger sized tumor was associated with higher probability of metastasis. We are in agreement, as our tumour $(11 \mathrm{~cm})$ showed PTC metastasis to the contralateral ovary. Nonetheless, it remains to be established whether the relationship between primary tumour size and metastasis is consistent for all MSO. For instance, others [22] reported two patients with metastasis despite their small primary tumors (first was $8 \mathrm{~mm}$ MSO tumour with contralateral ovarian metastasis; second comprised multiple small tumour foci in left ovary with metastasis to the liver).

In terms of management of the primary (ovarian) tumour, no standard guidelines exist for treatment of papillary thyroid carcinoma arising in MSO due to its scarcity. $\mathrm{TAH}+\mathrm{BSO}$ and omentectomy are considered optimal, however due to the permanent infertility associated with this procedure, unilateral salpingo-oopherectomy/unilateral oophorectomy in order to preserve the patients' fertility is suggested, as more aggressive approaches did not decrease the tumour's recurrence rate $[8,20,23]$. Our patient received $\mathrm{TAH}+\mathrm{BSO}$, in agreement with the published literature [18, 24].

As for recurrence, our primary tumour was in the left ovary with PTC metastasis to the right ovary, but we are unable to report on recurrence as our patient left Qatar (lost to follow up). Treatments for the primary ovarian tumor include: TAH + BSO (considered ideal), with no recurrence over 6 months - 4 years follow up [22, 24]; hysterectomy and unilateral oophorectomy/ unilateral salpingo-oopherectomy with no recurrence over 17 years [22, 25-27]; bilateral salpingo-oophrerectomy with no recurrence over $2-5$ years [28, 29]; and unilateral oophorectomy/ unilateral salpingo-oophorectomy with no recurrence over $1-25$ years [22, 30-35]. Our patient received $\mathrm{TAH}+\mathrm{BSO}$ that has good reported outcomes [22, 24, 29].

Whilst the role of ovarian cystectomy alone in managing MSO is unclear due to lack of data, ovarian cystectomy alone may be suboptimal as the patient may subsequently present with recurrences/ metastasis. For instance, a patient received ovarian cystectomy for SO with PTCF, but follow up and recurrence were not known [36]; another patient had right salpigo-oopherectomy for SO with mature cystic teratoma and enucleation of left ovarian cyst for PTCF, where multiple metastasis were subsequently found [37]; and two patients who had ovarian cystectomy as initial operations, both subsequently presented with metastasis [22]. Nevertheless, for patients with unilateral adnexal mass (unilateral MSO), both unilateral salpingo-oophrecetomy /unilateral oophorectomy and TAH seem effective. However, careful pre/operative assessment of the contralateral side and consistent post-operative follow up are recommended, as it may also harbor (benign or malignant) SO. Others found contralateral benign $\mathrm{SO}$ associated with unilateral $\mathrm{SO}$ tumor (not described whether malignant or benign) (4 cases) [18]; contralateral MSO PTCF associated with unilateral benign SO [37]; while both the current study and other reports [22] observed contralateral malignant metastatic deposits from the unilateral primary MSO tumour.

As for management of the thyroid gland itself, debate remains about the role of thyroidectomy and radioactive iodine ablation (T + RIA) for MSO. Most authors support aggressive treatment by surgical removal of the tumour followed by radiotherapy, chemotherapy and radioactive iodine therapy regardless of metastasis at time of diagnosis [4, 6, 38-41] (see also Table 1), and our MDT decision in managing our patient was in agreement with such an approach. Conversely, others hold that surgical removal of the ovarian tumour only is sufficient, and thyroidectomy and radioactive iodine to be undertaken in case of metastases or recurrent disease [42]. Certain SO characteristics may necessitate thyroidectomy and radioactive iodine therapy (e.g. tumor size $\geq 1 \mathrm{~cm}$, disease outside ovary, or histopathological features of aggressive tumor) [3, 43]. Moreover, MSO may actually increase the risk of additional thyroid cancer [23], where, among 68 MSO, 9\% had primary thyroid cancer in the neck, and $67 \%$ had invasive thyroid cancer disease [8]. Early genomic instability and gene mutations may provide a common pathogenesis for all papillary thyroid cancers irrespective of their body locations $[21,40]$.

\section{Conclusion}

This report is a comprehensive literature review of MSO, detailing the sizes and histopathological 


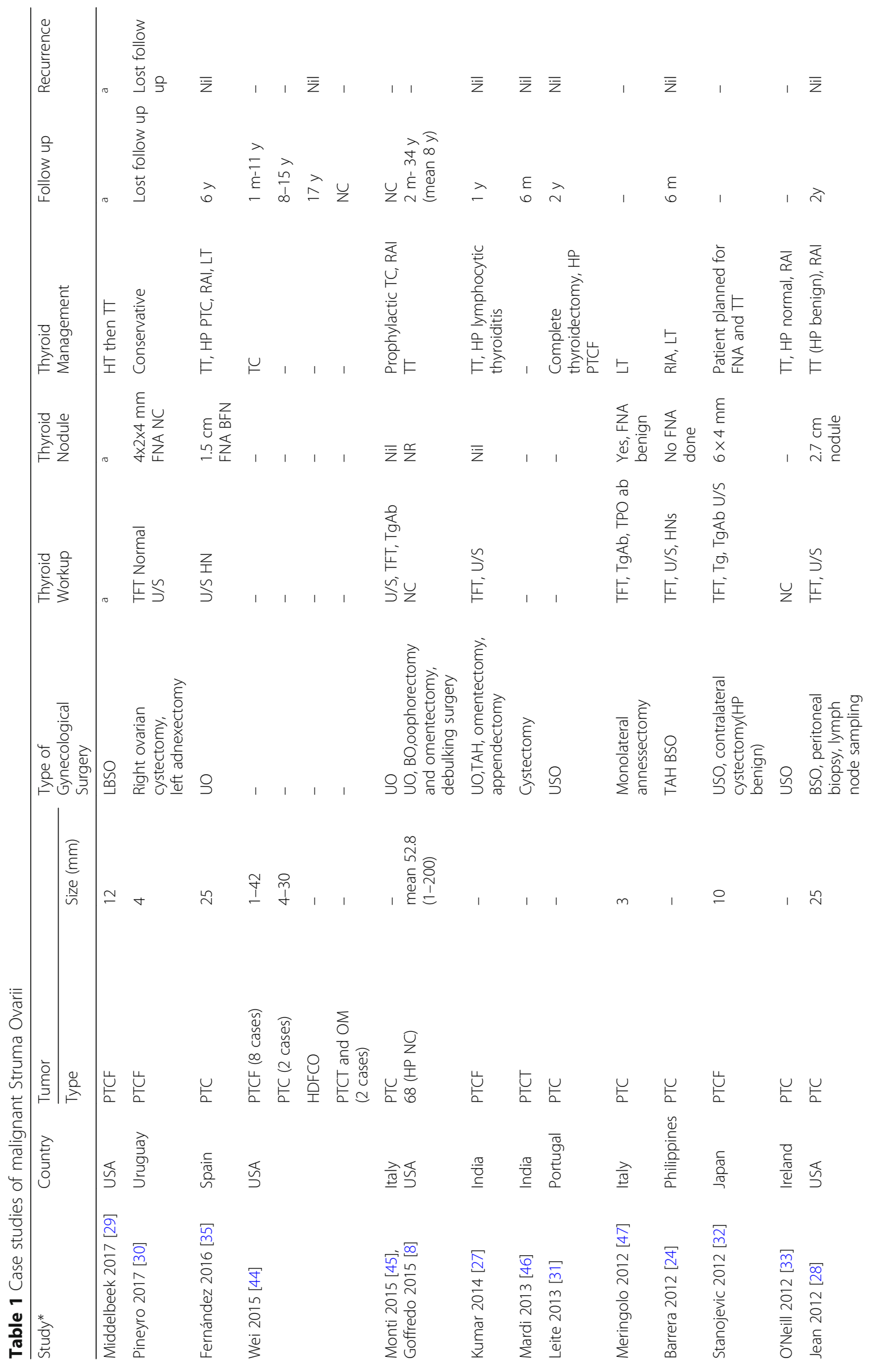




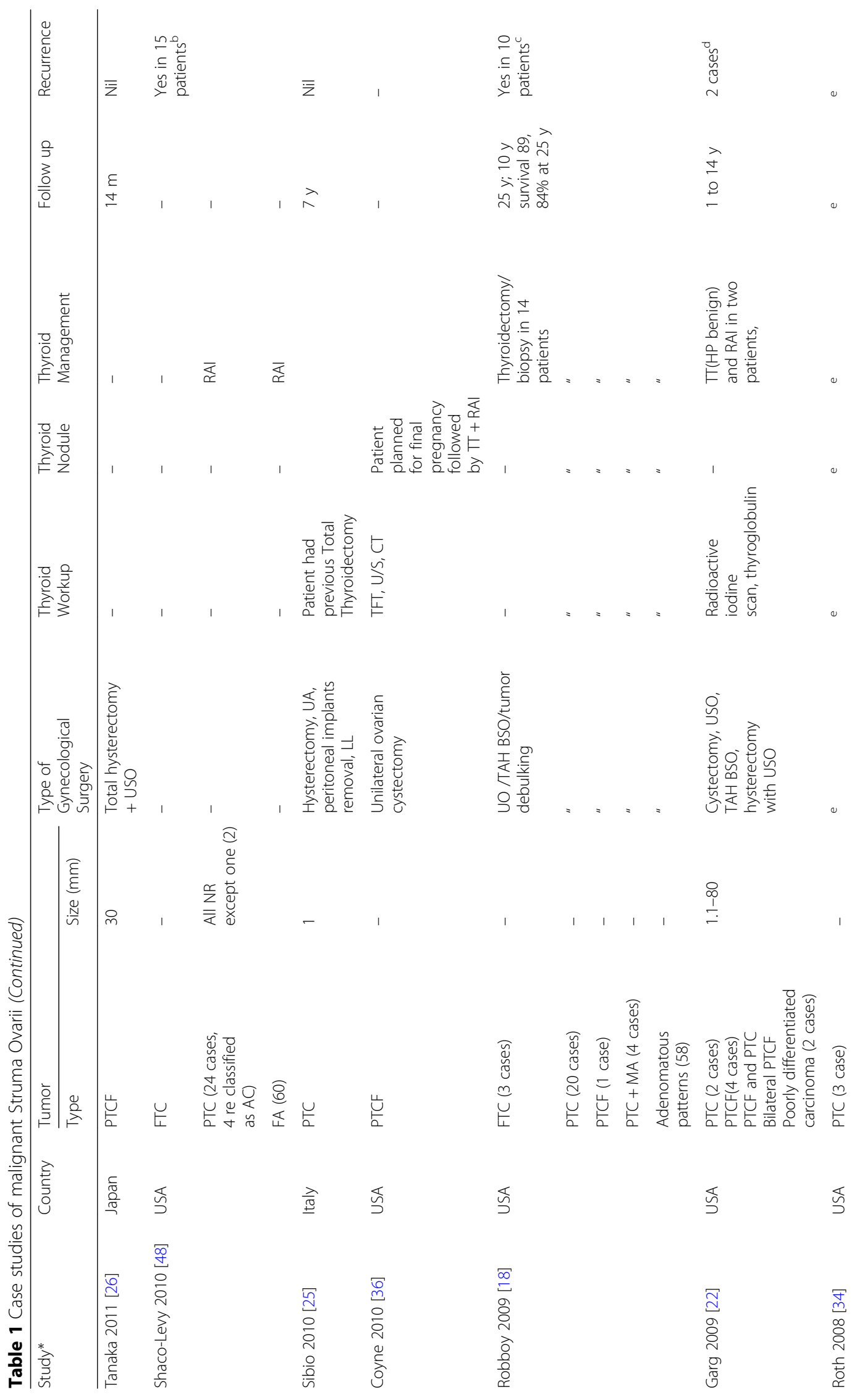




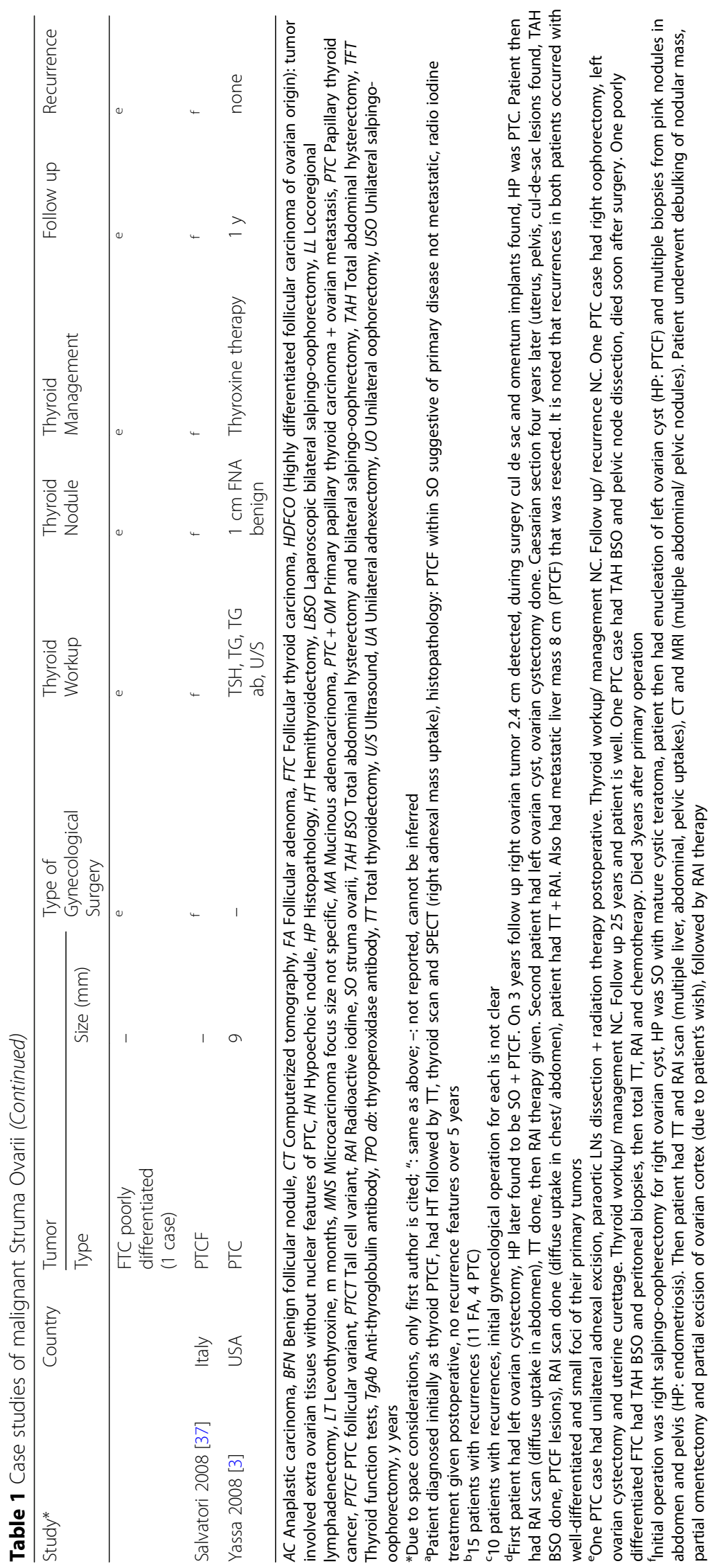


categories, types of gynecological surgery, thyroid gland workup and management, and follow up and recurrence. Our case report is possibly the largest MSO PTC in the literature. $\mathrm{TAH}+\mathrm{BSO}$ seems to be best in terms of curative outcome, however, hysterectomy with unilateral salpinogo-oophrectomy/unilateral oophorectomy, bilateral salpingo-oopherectomy and unilateral salpingo-oopherectomy/unilateral oophorectomy seem also effective treatment options. Fertility may be preserved with unilateral salpingo-oopherectomy/ unilateral oophorectomy, as this has great impact on the patient's psychology and social life. When unilateral removal of adnexal mass in undertaken, the contralateral side should be carefully assessed with surveillance for metastatic MSO. Ovarian cystectomy alone is associated with recurrences/ metastasis. Debate remains as to the association between MSO tumor size and potential extent of metastasis, and about the management of thyroid gland, however, surveillance and thyroid gland work up to detect concurrent thyroid cancer are recommended.

\begin{abstract}
Abbreviations
AJCC: American Joint Committee on Cancer; CT: Computerized tomography; MDT: Multi disciplinary team; MRI: Magnetic resonance imaging;

MSO: Malignant struma ovarii; PTC: papillary thyroid carcinoma; PTCF: papillary thyroid carcinoma follicular variant; SO: Struma ovarii; T + RIA: thyroidectomy and radioactive iodine ablation; T4: Thyroxine; TAH BSO: Bilateral salpingo-oopherectomy; TAH + BSO: Total abdominal hysterectomy and bilateral salpingo-oopherectomy; TAH: Total abdominal hysterectomy; TSH: Thyroid-stimulating hormone
\end{abstract}

\section{Acknowledgements}

Not applicable.

\begin{abstract}
Authors' contribution
MSA, TS and WEA wrote the first draft of the manuscript. AA contributed to the writing of the manuscript. MSA, TS, AA, HF, AAA and MZ contributed to the acquisition of the clinical data. WEA, AA, and TS jointly developed the structure and arguments of the paper. WEA, TS, AA, HF and MSA made critical revisions and approved the final version of the manuscript. All authors agreed with the manuscript results and conclusions and reviewed and approved the final manuscript.
\end{abstract}

\section{Funding}

Not applicable.

\section{Availability of data and materials}

Data sharing is not applicable to this article as no datasets were generated or analysed during the current study.

\section{Ethics approval and consent to participate}

Ethics approval and consent to publish provided (Medical Research Centre review board, IRB, \#16024/16, Hamad Medical Corporation, Doha, Qatar).

\section{Consent for publication}

Ethics approval and consent to publish provided (Medical Research Centre review board, IRB, \#16024/16, Hamad Medical Corporation, Doha, Qatar).

\section{Competing interests}

The authors declare that they have no competing interests.

\section{Publisher's Note}

Springer Nature remains neutral with regard to jurisdictional claims in published maps and institutional affiliations.

\section{Author details \\ ${ }^{1}$ Department of General Surgery, Hamad General Hospital, Doha, Qatar. ${ }^{2}$ Department of Surgery, Hamad General Hospital, Doha, Qatar. ${ }^{3}$ College of Medicine, Qatar University, Doha, Qatar. ${ }^{4}$ Department of Gynecologic Oncology, Hamad General Hospital, Doha, Qatar. ${ }^{5}$ Department of Endocrinology, Hamad General Hospital, Doha, Qatar. ${ }^{6}$ Department of Pathology, Hamad General Hospital, Doha, Qatar.}

Received: 31 May 2018 Accepted: 5 July 2018

Published online: 24 July 2018

\section{References}

1. Dunzendorfer T, deLas Morenas A, Kalir T, Levin RM. Struma ovarii and hyperthyroidism. Thyroid. 1999;9:499.

2. Kondi-Pafiti A, Mavrigiannaki P, Grigoriadis C, et al. Monodermal teratomas (struma ovarii). Clinicopathological characteristics of 11 cases and literature review. Eur J Gynaecol Oncol. 2011;32:657.

3. Yassa L, Sadow P, Marqusee E. Malignant struma ovarii. Nat Clin Pract Endocrinol Metab. 2008:4:469.

4. Yoo SC, Chang KH, Lyu MO, Chang SJ, Ryu HS, Kim HS. Clinical characteristics of struma ovarii. J Gynecol Oncol. 2008;19:135-8.

5. Kraemer B, Grischke EM, Staebler A, et al. Laparoscopic excision of malignant struma ovarii and 1 year follow-up without further treatment. Fertil Steril. 2011;95(6):2124.e9-12.

6. DeSimone CP, Lele SM, Modesitt SC. Malignant struma ovarii: a case report and analysis of cases reported in the literature with focus on survival and 1131 therapy. Gynecol Oncol. 2003;89:543-8.

7. McGill JF, Sturgeon C, Angelos P. Metastatic Struma ovarii treated with total thyroidectomy and radioiodine ablation. Endocr Pract. 2009;15(2):167-73.

8. Goffredo P, Sawka AM, Pura J, Adam MA, Roman SA, Sosa JA. Malignant struma ovarii: a population-level analysis of a large series of 68 patients. Thyroid. 2015;25(2):211-5.

9. Salman W, Singh M, Twaij Z. A case of papillary thyroid carcinoma in struma ovarii and review of the literature. Patholog Res Int. 2010;2010: 352476.

10. Tomee JF, van der Heijden PF, van den Hout JH, Brinkhuis M, Veneman TF. Papillary carcinoma in struma ovarii: an unusual presentation. Neth $J$ Med. 2008;66(6):248-51.

11. Sussman SK, Kho SA, Cersosimo E, Heimann A. Coexistence of malignant struma ovarii and Graves' disease. Endocr Pract. 2002;8(5):378-80.

12. Teale E, Gouldesbrough DR, Peacey SR. Graves' disease and coexisting struma ovarii: struma expression of thyrotropin receptors and the presence of thyrotropin receptor stimulating antibodies. Thyroid. 2006;16(8):791-3.

13. Talerman A. Germ cell tumors of the ovary. In: Kurman RJ, editor. Blaustein's pathology of the female genital tract. 3rd ed. New York: Springer Verlag; 2001. p. 967-1033.

14. Roth $L M$, Talerman A. The enigma of struma ovarii. Pathology. 2007;39(1):139-46.

15. Makani S, Kim W, Gaba AR. Struma Ovarii with a focus of papillary thyroid cancer: a case report and review of the literature. Gynecol Oncol. 2004;94:835.

16. Zalel Y, Seidman DS, Oren M, et al. Sonographic and clinical characteristics of struma ovarii. J Ultrasound Med. 2000;19:857.

17. Savelli L, Testa AC, Timmerman D, Paladini D, Ljungberg O, Valentin L. Imaging of gynecological disease (4): clinical and ultrasound characteristics of struma ovarii. Ultrasound Obstet Gynecol. 2008;32:210-9.

18. Robboy SJ, Shaco-Levy R, Peng RY, Snyder MJ, Donahue J, Bentley RC, Bean S, Krigman HR, Roth LM, Young RH. Malignant struma ovarii: an analysis of 88 cases, including 27 with extraovarian spread. Int J Gynecol Pathol. 2009; 28(5):405-22.

19. Nalbanski A, Pŭnevska M, Nalbanski B. Stromal ovary in 14 years old girl. Akush Ginekol (Sofiia). 2007;46(6):44-6. Bulgarian

20. Marti JL, Clark VE, Harper H, Chhieng DC, Sosa JA, Roman SA. Optimal surgical management of well-differentiated thyroid cancer arising in Struma ovarii: a series of 4 patients and a review of 53 reported cases. Thyroid. 2012;22:400-6.

21. Schmidt J, Derr V, Heinrich MC, Crum CP, Fletcher JA, Corless CL, Nosé V. BRAF in papillary thyroid carcinoma of ovary (struma ovarii). Am J Surg Pathol. 2007;31:1337-43. 
22. Garg K, Soslow RA, Rivera M, Tuttle MR, Ghossein RA. Histologically bland "extremely well differentiated" thyroid carcinomas arising in struma ovarii can recur and metastasize. Int J Gynecol Pathol. 2009;28(3):222-30.

23. Boyd JC, Williams BA, Rigby MH, Kieser K, Offman S, Shirsat H, Trites JRB, Taylor SM, Hart RD. Malignant Struma ovarii in a 30-year old nulliparous patient. Thyroid Res. 2017;30(10):3.

24. Barrera JR, Manalo LA, Ang FL. Papillary thyroid-type carcinoma arising from struma ovarii. BMJ Case Rep. 2012 11; 2012.

25. Sibio S, Borrini F, Sammartino P, Accarpio F, Biacchi D, Caprio G, lafrate F, Baccheschi AM, Cornali T, Di Giorgio A. Predominant Brenner tumor combined with struma ovarii containing a papillary microcarcinoma associated with benign peritoneal strumosis: report of a case and histologic features. Endocr Pathol. 2010;21(3):199-203.

26. Tanaka H, Sakakura Y, Kobayashi T, Yoshida K, Asakura T, Taniguchi H. A case of thyroid-type papillary carcinoma derived from ovarian mature cystic teratoma, resected by laparoscopic surgery. Asian J Endosc Surg. 2011;4(2):86-9.

27. Kumar SS, Rema P, R AK, Varghese BT. Thyroid type papillary carcinoma arising in a mature teratoma. Indian J Surg Oncol. 2014;5(3):168-70.

28. Jean S, Tanyi $J$, Montone $K$, et al. Papillary thyroid cancer arising in struma ovarii. J Obstet Gynaecol. 2012;32:222

29. Middelbeek RJW, O'Neill BT, Nishino M, Pallotta JA. Concurrent thyroid Cancer in Struma Ovarii: a case report and literature review. J Endocr Soc 2017 23;1(5):396-400.

30. Pineyro MM, Pereda J, Schou P, de Los Santos K, de la Peña S, Caserta B, Pisabarro R. Papillary thyroid microcarcinoma arising within a mature OvarianTeratoma: case report and review of the literature. Clin Med Insights Endocrinol Diabetes. 2017;10 https://doi.org/10.1177/1179551417712521.

31. Leite I, Cunha TM, Figueiredo JP, Félix A. Papillary carcinoma arising in struma ovarii versus ovarian metastasis from primary thyroid carcinoma: a case report and review of the literature. J Radiol Case Rep. 2013 Oct; 7(10):24-33.

32. Stanojevic B, Dzodic R, Saenko V, Milovanovic Z, Krstevski V, Radlovic P, Buta M, Rulic B, Todorovic L, Dimitrijevic B, Yamashita S. Unilateral follicular variant of papillary thyroid carcinoma with unique KRAS mutation in struma ovarii in bilateral ovarian teratoma: a rare case report. BMC Cancer. 2012;8(12):224.

33. O'Neill JP, Burns P, Kinsella J. Papillary type thyroid carcinoma in an ovarian struma. Ir J Med Sci. 2012;181(1):115-7.

34. Roth LM, Karseladze Al. Highly differentiated follicular carcinoma arising from struma ovarii: a report of 3 cases, a review of the literature, and a reassessment of so-called peritoneal strumosis. Int J Gynecol Pathol. 2008; 27(2):213-22.

35. Fernández Catalina $P$, Rego Iraeta A, Lorenzo Solar M, Sánchez Sobrino P. Sincronous malignant struma ovarii and papillary thyroid carcinoma. Endocrinol Nutr. 2016;63(7):366-7.

36. Coyne C, Nikiforov YE. RAS mutation-positive follicular variant of papillary thyroid carcinoma arising in a struma ovarii. Endocr Pathol. 2010;21(2):144-7.

37. Salvatori M, Dambra DP, D'Angelo G, Conte LL, Locantore P, Zannoni G, Campo V. Campo S. A case of metastatic struma ovarii treated with 131 therapy: focus on preservation of fertility and selected review of the literature. Gynecol Endocrinol. 2008:24(6):312-9.

38. Zhu Y, Wang C, Zhang GN, Shi Y, Xu SQ, Jia SJ, He R. Papillary thyroid cancer located in malignant struma ovarii with omentum metastasis: a case report and review of the literature. World J Surg Oncol. 2016;20(14):1-17.

39. Shrimali RK, Shaikh G, Reed NS. Malignant struma ovarii: the west of Scotland experience and review of literature with focus on postoperative management. J Med Imaging Radiat Oncol. 2012;56:478-82.

40. Leong A, Roche PJ, Paliouras M, Rochon L, Trifiro M, Tamilia M. Coexistence of malignant struma ovarii and cervical papillary thyroid carcinoma. J Clin Endocrinol Metab. 2013;98:4599-605.

41. Matysiak-Grzes M, Fischbach J, Gut P, Klimowicz A, Gryczynska M, Wasko R, Ruchala M. Struma ovarii maligna. Neuro Endocrinol. 2013;34:97-101.

42. Zhang $X$, Axiotis C. Thyroid-type carcinoma of Struma ovarii. Arch Pathol Lab Med. 2010;34:786-91.

43. Janszen EW, van Doorn HC, Ewing PC, de Krijger RR, de Wilt JH, Kam BL, et al. Malignant Struma ovarii: good response after thyroidectomy and I ablation therapy. Clin Med Oncol. 2008;2:147-52.

44. Wei S, Baloch ZW, LiVolsi VA. Pathology of Struma Ovarii: a report of 96 cases. Endocr Pathol. 2015;26(4):342-8.
45. Monti E, Mortara L, Zupo S, Dono M, Minuto F, Truini M, Naseri M, Giusti M. Papillary thyroid cancer in a struma ovarii: a report of a rare case. Hormones (Athens). 2015;14(1):154-9.

46. Mardi K, Gupta N. Tall cell variant of papillary carcinoma arising from strumaovarii: a rare case report. J Cancer Res Ther. 2013;9(1):119-21.

47. Meringolo D, Bianchi D, Capula C, Costante G. Papillary thyroid microcarcinoma in struma ovarii. Endocrine. 2012;41(1):164-5.

48. Shaco-Levy R, Bean SM, Bentley RC, Robboy SJ. Natural history of biologically malignant struma ovarii: analysis of 27 cases with extraovarian spread. Int J Gynecol Pathol. 2010;29(3):212-27.

\section{Ready to submit your research? Choose BMC and benefit from:}

- fast, convenient online submission

- thorough peer review by experienced researchers in your field

- rapid publication on acceptance

- support for research data, including large and complex data types

- gold Open Access which fosters wider collaboration and increased citations

- maximum visibility for your research: over $100 \mathrm{M}$ website views per year

At BMC, research is always in progress.

Learn more biomedcentral.com/submissions 